\title{
REPARATIVE REGENERATION OF PERIAPICAL TISSUES IN CHRONIC GRANULOMATOUS PERIODONTITIS UNDER THE INFLUENCE OF COMPOSITION BASED ON CALCIUM HYDROXYAPATITE
}

DOI: 10.36740/WLek202104104

\author{
Iryna V. Han, Volodymyr M. Zubachyk, Khrystyna H. Musij-Sementsiv, Nataliia I. Bodnaruk, Nataliia V. Porokhovska, \\ Oksana M. Slaba \\ DANYLO HALYTSKY LVIV NATIONAL MEDICAL UNIVERSITY, LVIV, UKRAINE
}

\begin{abstract}
The aim: To establish the dynamics of reparation processes in periapical tissues in chronic granulomatous periodontitis under the influence of the developed composition based on calcium hydroxyapatite in comparison with the generally accepted drug MTA.

Materials and methods: The main group included 52 individuals, and the comparison group - 19 patients with chronic granulomatous periodontitis. In the first experimental subgroup, patients were obturated of the tooth root apical area with the proposed composition, and in the second experimental subgroup patients were performed obturation of the root canal apical area with additional transcanal withdrawal of the composition into the periapical area. In the comparison group, the tooth root apex was obturated with MTA material.

Results: Clinical studies have shown that the composition based on calcium hydroxyapatite, having osteoconductive, antioxidant and anti-inflammatory properties, activates the synthesis of organic and mineral components, that promotes the bioreparation and regeneration processes of periapical tissues in chronic granulomatous periodontitis, which occurred most intensively during the first 6 months after treatment. At the same time, with additional transcanal removal of the filling composition based on calcium hydroxyapatite into the periapical area in patients with chronic granulomatous periodontitis with acquired wide tooth root apex was observed in 1.6 time better results than the method of creating an apical root canal obturation $(p<0,05)$, indicating a high therapeutic effect.

Conclusions: Composition based on calcium hydroxyapatite, having osteoconductive, antioxidant and anti-inflammatory properties, activates the synthesis of organic and mineral components, which promotes the processes of bioreparation and regeneration of periapical tissues, especially in the early stages. And additional transcanal removal of the filling composition into the periapical space causes the acceleration of the period of periodontal tissues revitalization, bioreparation and regeneration compared to the creation of the apical obturation within the physiological tooth root apex.
\end{abstract}

KEY WORDS: granulomatous periodontitis; composition based on calcium hydroxyapatite; regeneration; CDAP index

Wiad Lek. 2021;74(4):832-837

\section{INTRODUCTION}

The bone tissue regeneration after its damage by various factors remains an urgent problem, both for medicine in general and for dentistry in particular [1-4]. With the latest technologies and inventions, the prevalence of complicated caries is not only not reduced, but, according to some authors, increases, which is associated with the complexity of endodontic treatment and quite often with the absence of long-lasting positive results after its completion [5-10].

In the conservative treatment of patients with chronic forms of periodontitis, the main tasks remain the influence on the microflora of macro- and microchannels with the aim of their sterilization, hermetic root canals obstruction to prevent root canal reinfection and direct influence on the periapical tissues with the aim of stimulation of regenerative processes in the area beyond the apex, both by enhancing the body's defenses and by influencing the components of the endodontic filling material to accelerate reparative processes in the periapical area [11-15].

Thus, the high prevalence of chronic forms of periodontitis causes the constant improvement of already developed types of endodontic medicine and the search for new means and methods for tight obturation of the tooth root apex and stimulation of the revitalization and regeneration of periapical tissues $[16,17]$.

\section{THE AIM}

To establish the dynamics of reparation processes in periapical tissues in chronic granulomatous periodontitis under the influence of the developed composition based on calcium hydroxyapatite in comparison with the generally accepted drug MTA. 


\section{MATERIALS AND METHODS}

71 people aged 20 to 59 years, who were suffering from chronic granulomatous periodontitis, were under our observation. All teeth were single-rooted with the width of the root apex 40 to 80 per ISO. Patients provided voluntary written consent to conduct a clinical trial. The study was confirmed and approved by the ethics committee of Danylo Halytsky Lviv National Medical University.

The patients were divided into two groups: the main group consisted of 52 individuals and the comparison group - 19 patients. The main group, according to the technique of root canal filling, was divided into two subgroups: patients in the first experimental subgroup were obturated apical section of the tooth root by our proposed composition containing calcium hydroxyapatite, a means for revitalization and bioreparation of periapical tissues, $40 \%$ polyvinylpyrrolidone and barium sulfate (patent of Ukraine № 95974) by creation the apical obturation (patent of Ukraine № 95967) [18, 19]; patients in the second experimental subgroup were obturated the apical section of the root canal with additional transcanal removal of the composition into the periapical area.

The condition of periapical tissues was evaluated on the basis of complaints, anamnesis, objective data and an additional examination method - radiography [20, $21,22]$. Patients were made intra-oral radiography of the teeth during the initial examination, after completion of endodontic treatment and at the stages of dispensary observation in the control periods: 6, 12 and 18 months. The quality of root canal obturation was evaluated and the magnitude of the destruction of changes beyond the apex was diagnosed using the periapical index of the condition of destruction of apical periodontitis (CDAP) in scores E.O. Skapkareva, 2003 [23, 24].

Patients with chronic granulomatous periodontitis of the comparison group after antiseptic treatment of the oral cavity were performed carious cavity preparation and tooth cavity opening, thereafter an access to root canals was created, the tissue breakdown products were evacuated, the length of the root canal was measured by apexlocator using a K-file and X-ray method. Mechanical cleansing and extension of the root canal were performed by the "Crown down" technique using an endomotor. The crown part of the root canal was worked out by Shaper endodontic instruments, and ProFile instruments of various sizes and tapers were used for the middle and the apical part of the root canal, not reaching the anatomical tooth root apex by 3-4 mm. The apex part of the root canal was worked out with hand-held $\mathrm{K}$-and $\mathrm{H}$-file type endodontic instruments with sizes from № 40 to № 80 according to ISO using the "RC-prep" endogel ("Premier Dental", USA) for root canal. Instrumental processing of the root canals was completed at the level of the anatomical apex of the root canal under the control of the apexlocator and radiographic method. Medical root canal treatment was performed using endodontic syringes with irrigation solutions, which included $3 \%$ hydrogen peroxide solution, 3\% and 5,25\% sodium hypochlorite solution and distilled water. After drying, the root canal was filled with calcium-containing paste «Calasept» («Nordiska Dental», Sweden) and a temporary seal was applied. At the second visit, after repeated antibacterial and instrumental treatment of the canal, the root apex was covered with MTA material ("Cercamed", Poland) and a temporary seal was applied. At the third visit, the canal from the apical obturation level and to the root canal orifices was sealed by central pin method or lateral condensation method with AH Plus material ("Dentsply», USA) in combination with gutta-percha pins. Thereafter, the anatomical shape of the crown part of the tooth was restored with photopolymeric light solidification materials. X-ray examination was performed during the initial examination, after completion of endodontic treatment and at the stages of dispensary observation in the central pin or cold lateral condensation with the restoration in control dates.

Treatment of patients with chronic granulomatous periodontitis of the main group was carried out according to the basic method. After the opening of the tooth cavity, evacuation of putrid masses, mechanical expansion and antiseptic treatment of the root canal with the purpose of prolonged impact on the periapical tissues, a paper pin, soaked in the means for revitalization and bioreparation, was left inside. The solution contained hyaluronic acid modified with vitamin $\mathrm{C}$ and amino acids - proline, lysine and glycine, as well as $1 \%$ collagen hydrolyzate, $6 \%$ 2-dimethylaminomethanol 4-acetoaminobenzoate and $1 \%$ organic silicon in equal proportions of components (patent of Ukraine № 85259). For the purpose of obturation of the apical part of the root canal (patent of Ukraine № 95967) and the removal of the therapeutic agent in the area beyond apex, a composition in the form of a medicinal paste was developed, which composition included the ingredients mentioned above and calcium hydroxyapatite as well as excipients: polyvinylpyrrolidone and barium sulfate (patent of Ukraine № 95974) [25]. For the apical obturation of the root canal by the composition, plaggers of appropriate sizes were used, and the removal of the composition was transcanal carried out using channel fillers "Lentulo" 30-40 sizes. A cotton ball was placed on the root canal orifices and the tooth was closed with a temporary seal for 1-2 days. In the subsequent visit, the canal from the apical obturation level and to the root canal orifices was sealed by the method of anatomical tooth shape with light solidification composite materials.

\section{RESULTS}

During the examination of patients with chronic granulomatous periodontitis, it was found that only two patients in the main group $(3,9 \%)$ had a complaint of minor pain while eating immediately after treatment (Table 1). By the second or third day, all signs of inflammation had gone away without further treatment. In the other patients - 52 persons $(96,1 \%)$ of the experimental group, we observed restoration of tooth function, which testifies to the positive dynamics of their treatment. 
Table I. Criteria for the effectiveness of treatment of patients with chronic granulomatous periodontitis immediately after its conduct

\begin{tabular}{|c|c|c|c|c|c|c|c|c|c|}
\hline \multicolumn{2}{|c|}{ Examination groups } & \multicolumn{2}{|c|}{ Complaints } & \multicolumn{2}{|c|}{$\begin{array}{l}\text { Pain during } \\
\text { percussion }\end{array}$} & \multicolumn{2}{|c|}{$\begin{array}{l}\text { Mucous edema in } \\
\text { root apex projection }\end{array}$} & \multicolumn{2}{|c|}{$\begin{array}{l}\text { Restoration of } \\
\text { tooth function }\end{array}$} \\
\hline & & yes & no & yes & no & yes & No & yes & No \\
\hline \multirow{3}{*}{$\begin{array}{l}\text { Comparison group, } \\
\qquad n=19\end{array}$} & abs. & 5 & 14 & 5 & 14 & 4 & 15 & 14 & 5 \\
\hline & $\%$ & 26,3 & 73,7 & 26,3 & 73,7 & 21,1 & 78,9 & 73,7 & 26,3 \\
\hline & $\begin{array}{l}\text { the average indicator } \\
\text { in the group }\end{array}$ & \multicolumn{2}{|c|}{$0,26 \pm 0,1$} & \multicolumn{2}{|c|}{$0,26 \pm 0,1$} & \multicolumn{2}{|c|}{$0,21 \pm 0,1$} & \multicolumn{2}{|c|}{$0,26 \pm 0,1$} \\
\hline \multirow{3}{*}{$\begin{array}{c}\text { The first } \\
\text { experimental } \\
\text { subgroup, } \\
n=28\end{array}$} & abs. & 1 & 27 & 1 & 27 & 0 & 28 & 27 & 1 \\
\hline & $\%$ & 3,6 & 96,4 & 3,6 & 96,4 & 0 & 100 & 96,4 & 3,6 \\
\hline & $\begin{array}{l}\text { the average indicator } \\
\text { in the group }\end{array}$ & \multicolumn{2}{|c|}{$0,06 \pm 0,04$} & \multicolumn{2}{|c|}{$0,06 \pm 0,04$} & \multicolumn{2}{|c|}{0} & \multicolumn{2}{|c|}{$0,06 \pm 0,04$} \\
\hline \multirow{3}{*}{$\begin{array}{l}\text { The second } \\
\text { experimental } \\
\text { subgroup, } \\
n=24\end{array}$} & abs. & 1 & 23 & 1 & 23 & 0 & 24 & 23 & 1 \\
\hline & $\%$ & 4,2 & 95,8 & 4,2 & 95,8 & 0 & 100 & 95,8 & 4,2 \\
\hline & $\begin{array}{l}\text { the average indicator } \\
\text { in the group }\end{array}$ & \multicolumn{2}{|c|}{$0,04 \pm 0,04^{*}$} & \multicolumn{2}{|c|}{$0,04 \pm 0,04$} & \multicolumn{2}{|c|}{0} & \multicolumn{2}{|c|}{$0,04 \pm 0,04$} \\
\hline
\end{tabular}

Note: * the probability indicator of difference between the average indicators compared to the comparison group at $p<0,05$

Table II. Criteria for the effectiveness of treatment of patients with chronic granulomatous periodontitis after 6 months

\begin{tabular}{|c|c|c|c|c|c|c|c|c|}
\hline \multicolumn{2}{|c|}{ Comparison groups } & \multicolumn{2}{|c|}{$\begin{array}{l}\text { Complaints in } \\
\text { anamnesis }\end{array}$} & \multicolumn{2}{|c|}{$\begin{array}{l}\text { Pain during } \\
\text { percussion }\end{array}$} & \multicolumn{2}{|c|}{$\begin{array}{l}\text { Restoration of } \\
\text { tooth function }\end{array}$} & \multirow[t]{2}{*}{ The CDAP index } \\
\hline & & yes & no & yes & no & yes & No & \\
\hline \multirow{3}{*}{$\begin{array}{l}\text { Comparison group, } \\
\qquad \mathrm{n}=19\end{array}$} & abs. & 4 & 15 & 4 & 15 & 15 & 4 & \multirow{3}{*}{$3,9 \pm 0,27$} \\
\hline & $\%$ & 21 & 79 & 21 & 79 & 79 & 21 & \\
\hline & $\begin{array}{c}\text { the average indicator } \\
\text { in the group }\end{array}$ & \multicolumn{2}{|c|}{$0,21 \pm 0,1$} & \multicolumn{2}{|c|}{$0,21 \pm 0,1$} & \multicolumn{2}{|c|}{$0,21 \pm 0,1$} & \\
\hline \multirow{3}{*}{$\begin{array}{l}\text { The first subgroup of } \\
\text { the main group, } \\
\qquad n=28\end{array}$} & abs. & 1 & 27 & 1 & 27 & 27 & 1 & \multirow{3}{*}{$3,2 \pm 0,16^{*}$} \\
\hline & $\%$ & 4 & 96 & 4 & 96 & 96 & 4 & \\
\hline & $\begin{array}{l}\text { the average indicator } \\
\text { in the group }\end{array}$ & \multicolumn{2}{|c|}{$0,04 \pm 0,04$} & \multicolumn{2}{|c|}{$0,04 \pm 0,04$} & \multicolumn{2}{|c|}{$0,04 \pm 0,04$} & \\
\hline \multirow{3}{*}{$\begin{array}{l}\text { The second subgroup } \\
\text { of the main group, } \\
\qquad n=24\end{array}$} & abs. & 0 & 24 & 0 & 24 & 24 & 0 & \multirow{3}{*}{$2,8 \pm 0,17^{* * *}$} \\
\hline & $\%$ & 0 & 100 & 0 & 100 & 100 & 0 & \\
\hline & $\begin{array}{l}\text { the average indicator } \\
\text { in the group }\end{array}$ & \multicolumn{2}{|c|}{0} & \multicolumn{2}{|c|}{0} & \multicolumn{2}{|c|}{0} & \\
\hline
\end{tabular}

Note: ${ }^{*}$ - the probability indicator of difference compared to the comparison group at $p<0,05 ;{ }^{* * *}$ - at $p<0,001$.

In the comparison group, complaints of pain during tingling and positive percussion of the causative tooth immediately after the treatment were observed in 5 patients (21\%), apart from this, 3 of them (10,7\%) showed swelling in the transient convolution of the oral mucosa in the area of the oral cavity in the tooth root apex and tenderness during its palpation. All patients with exacerbation of the inflammatory process were prescribed the drug "Nurofen". After conducting of additional treatment for ten days, all signs of exacerbation of the inflammatory process were eliminated.

At the same time, the results of the studies indicate that the index of CDAP in patients with chronic granulomatous periodontitis of the main group both of the first and second subgroups was $4,3 \pm 0,18$ point, and in the comparison group $-4,4 \pm 0,23$ point, that indicates on the primary approximately the same severity of destruction processes in periapial tissues in patients with chronic granulomatous periodontitis.

The effectiveness of treatment largely depends not only on the means, but also the method used in the treatment of this pathology. During the control examination of patients with chronic granulomatous periodontitis with acquired tooth root apex, it was observed the maintenance of functional activity of the tooth in $96,4 \%$ and $100 \%$ of patients 6 months after the endodontic treatment in the first and second subgroups of the main group. Only one patient $(3,6 \%)$ of the first subgroup complained of minor periodic discomfort when biting a tooth. In the comparison group, the preserved functional tooth activity was noted in $79 \%$ of patients, which is $20 \%$ less than in the main group. This 
Table III. Meaning of the CDAP index indicators (points) of patients with chronic granulomatous periodontitis 12 months after treatment

\begin{tabular}{|c|c|c|c|}
\hline \multirow[b]{2}{*}{ Terms of examination } & \multicolumn{3}{|c|}{ Examination groups } \\
\hline & $\begin{array}{l}\text { Comparison group, } \\
\qquad n=19\end{array}$ & $\begin{array}{l}\text { Main group, } \\
\text { subgroup 1, } \\
\quad \mathbf{n}=\mathbf{2 8}\end{array}$ & $\begin{array}{c}\text { Main group, } \\
\text { subgroup } 2, \\
n=24\end{array}$ \\
\hline 6 months & $3,9 \pm 0,27$ & $3,2 \pm 0,16$ & $2,8 \pm 0,17$ \\
\hline 12 months & $3,4 \pm 0,31^{* *}$ & $2,4 \pm 0,19 \underset{o}{* * *}$ & $1,7 \pm 0,2 \underset{\text { o o o }}{* * * 0}$ \\
\hline
\end{tabular}

Note: ${ }^{* *}$ - the probability indicator of difference compared to the results on 6 month of the study at $p<0,01$; ${ }^{* * *}$ - at $p<0,001$; $^{\circ}$ - the probability indicator of difference compared to the comparison group at $p<0,05 ;{ }^{\circ 00}$ - at $p<0,001 ; \diamond$ - the probability indicator of difference between the subgroups of the main group at $p<0,05$.

Table IV. Meaning of the CDAP index indicators (points) of patients with chronic granulomatous periodontitis 18 months after treatment

\begin{tabular}{|c|c|c|c|}
\hline \multirow[b]{2}{*}{ Terms of examination } & \multicolumn{3}{|c|}{ Examination groups } \\
\hline & $\begin{array}{l}\text { Comparison group, } \\
\qquad n=19\end{array}$ & $\begin{array}{l}\text { Main group, } \\
\text { subgroup 1, } \\
\qquad n=28\end{array}$ & $\begin{array}{l}\text { Main group, } \\
\text { subgroup } 2, \\
n=24\end{array}$ \\
\hline 12 months & $3,4 \pm 0,31$ & $2,4 \pm 0,19$ & $1,7 \pm 0,2$ \\
\hline 18 months & $2,4 \pm 0,42^{* * *}$ & $1,3 \pm 0,19 \underset{0}{* * *}$ & $0,8 \pm 0,17_{0 \circ 0}^{* * *}$ \\
\hline
\end{tabular}

Note: $*^{* * *}$ - the probability indicator of difference compared to the group immediately after treatment at $p<0,001 ;^{\circ}$-the probability indicator of difference compared to the comparison group at $p<0,05 ;{ }^{\circ 00}$ at $-p<0,001$.

is due to the presence of complaints in the anamnesis of 4 patients, which was $21 \%$. At the same time, the pain and edema were not detected and percussion of the causative tooth was not painful at the time of examination and palpation of the mucous membrane in the area of the tooth root apex.

In all patients of the main group with chronic granulomatous periodontitis there was observed a decrease in the area of destruction of bone tissue and its replacement on the edges of lesions with a healthy bone tissue on radiographs after 6 months after the treatment (Table 2). It was also noted a decrease in the volume of excretion of the filling composition into the extracellular space in patients of the second subgroup. Instead, in the comparison group, only 2 patients $(10,5 \%)$ had an increase in the area of the lesion beyond the apex, and the lesion of 5 people (26\%) remained unchanged. Thus, the analysis of the results shows that only $63 \%$ of patients in the comparison group had a positive dynamics after conducted treatment, which was $37 \%$ less than the main group. At the same time, the average indicator of the CDAP index in the first subgroup of the main group was $3,2 \pm 0,16$ point, in the second subgroup $-2,8 \pm 0,17$ point, and in the comparison group, the average index was $3,9 \pm 0,27$ point. The results indicate that it was 1,2 time and 1,4 time lower in the first and second subgroups, respectively, compared to the control group and statistically significant $(\mathrm{p}<0,001)$.

After 12 months after treatment, analyzing the results of clinical examination of patients with chronic granulomatous periodontitis, it was established the preserved functional activity of the tooth in $100 \%$ of patients in the main group, and in the comparison group only in $84 \%$ of people (16 patients) (Table 3). During the X-ray study, all patients of the main group were observed a further reduction of the bone thinning area and replacement it with a newly formed bone, and patients of the second subgroup of the main group were noted the further integration of the components of the composition in the regeneration processes. However, the positive dynamics in the comparison group was observed only in $84 \%$ of patients, and in 2 patients $(10,5 \%)$ we found an increase in the size of destruction of changes beyond the apex, and in one patient $(5,3 \%)$ - it remained unchanged. In the first subgroup, the average index of the CDAP index decreased by 0,8 point and became $2.4 \pm 0.19$ point, and in the second subgroup - by 1,1 point and became $1,7 \pm 0,2$ point $(\mathrm{p}<0,05)$. At the same time, in the comparison group it was decreased by only 0,5 point and became $3,4 \pm 0,31$ point $(p<0,01$ ). In $11 \%$ of patients in the comparison group, the CDAP index increased or remained unchanged, indicating that there was no positive dynamics. However, in all patients of the main group, the CDAP index decreased, indicating $100 \%$ positive dynamics of regeneration processes in the periapical zone, and the fact that method of additional transcanal filling creates the favorable conditions for reducing the time of regeneration.

During the clinical examination of patients with chronic granulomatous periodontitis with acquired wide tooth root apex, it was observed in $100 \%$ of cases the preserved functional activity of the tooth in the main group after 18 months after treatment, and in the comparison group in $84 \%$ of people (16 patients), (Table 4 ). During the analysis of the results of radiological examination in the treatment by the method of creating apical obturation with the developed composition, complete recovery of periapical tissues was noted in 8 people (28.6\%), and with additional transcanal removal of this composition into the periapical space - in 11 patients (46\%). However, in the comparison group, restoration of periapical tooth tissues was observed in only 3 patients, which amounted to $15,7 \%$, and in 5 
patients (18\%) the CDAP index remained unchanged. In the first experimental subgroup it decreased by 0,9 point and was $1,3 \pm 0,19$ point, and in the second subgroup by 1,1 point $-0,8 \pm 0,17$ point, which is statistically significant $(\mathrm{p}<0,001)$. In the comparison group, the average index decreased by 1,0 point $(\mathrm{p}<0,001)$. The structure and volume of the root canal obturation was preserved in all patients and at all stages of the patient monitoring.

\section{DISCUSSION}

In our opinion, the significantly lower percentage of exacerbations in patients of the main group is due to the influence of the composition components having anti-inflammatory and antioxidant effect on the periapical tissues of the tooth $[22,24]$.

The effectiveness of treatment largely depends not only on the means, but also the method used in the treatment of this pathology. The decrease in the area of bone tissue destruction and its replacement at the edges of the lesion with the healthy bone tissue in persons of the first subgroup, as well as the reduction of the volume of the filling composition withdrawn into the area beyond the apex in persons of the second subgroup of the main group testify to the ability of the composition to biodestruction under conditions of destructively altered periodontal tissues and inclusion of its components in the regenerative process of the new bone tissue formation $[15,16]$.

It should be noted that provoding the treatment of chronic granulomatous periodontitis with the use of the proposed composition in the examination after 6 months it was obtained better results than the general method of treatment using the drug MTA. In our opinion, such a positive result of treatment of the patients of the main group is associated with the anti-inflammatory, osteotropic and antioxidant properties of the composition based on HA, which promoted acceleration of the regeneration processes. At the same time, it was noted the direct dependence of the treatment results in the main group on the method of filling the root canals, which was more effective in case of withdrawal of the composition into the periapical space $[9,11,17]$.

According to clinical and radiological studies of patients 12 months after treatment, we can state that the frequency of exacerbation cases of the inflammatory process in patients with chronic granulomatous periodontitis is higher when sealing with the drug MTA compared to the proposed composition. And the speed of the regeneration process is better when applying a composition based on calcium hydroxyapatite compared to the generally accepted drug MTA. In $11 \%$ of patients in the comparison group, the CDAP index increased or remained unchanged, indicating that there was no positive trend. At the same time, the CDAP index decreased in all patients of the main group, indicating $100 \%$ positive dynamics of regeneration processes in the periapical zone, and the method of additional transcannal filling creates favorable conditions for reducing the time of regeneration $[10,24]$.
The results of studies throughout the observation period for patients with chronic granulomatous periodontitis showed that the intensity of the regeneration processes was quite high with the highest activity during the first 6 months after treatment. Additional transcanal removal of the composition into the area beyond the apex was 1,6 time more effective after 18 months compared to the group where the treatment was performed by the method of apical obturation $(p<0,05)[17]$.

Summarizing the results of the study, it can be argued that the composition based on calcium hydroxyapatite furthers the acceleration of the regeneration processes in the periapical area and the reduction of the recovery time of patients with granulomatous periodontitis. In particular, the results of the study indicate that the most intensive regeneration processes in patients of granulomatous periodontitis of the main group took place during the first 6 months of observation after treatment. In our opinion, this is due to the influence of organic components of the composition, which during this period are more intensively releasing from the dosage form and stimulate bioregeneration processes and exhibit anti-inflammatory properties. At a stage of 12-18 months, a similar trend remains, which is due to the osteoconductive properties of hydroxyapatite $[7,15,16]$.

\section{CONCLUSIONS}

1. Composition based on calcium hydroxyapatite, having osteoconductive, antioxidant and anti-inflammatory properties, activates the synthesis of organic and mineral components, which furthers the processes of bioreparation and regeneration of periapical tissues in chronic granulomatous periodontitis, especially in the early stages.

2. Additional trans-channel withdrawal of the filling composition into the periapical area causes the acceleration of the revitalization, bioreparation and regeneration periods of periodontal tissues compared to the creation of an apical obturation within the physiological apex of the tooth root, which provides a high therapeutic effect.

3 . For the treatment of patients with chronic granulomatous periodontitis, especially with the acquired apex of the root of the tooth, in order to accelerate the repair processes of the tissue beyond the apex, it is possible to recommend the proposed osteotropic composition based on calcium hydroxyapatite, which will stimulate the biorevitalization and reparation of tissues beyond the apex.

\section{REFERENCES}

1. Noor E., AL-Bayaty F. A review on predisposing and modifying factors of periodontal disease. Journal of Advanced Medical Research. 2015; 5(1):5-23.

2. Louis M., George T., Huang J. Regeneration and Repair in Endodontics. A Special Issue of the Dentistry Journal. Dent J. 2015; 3(3):77-78.

3. Saoud T., Ricucci D., Lin L. Regeneration and repair in endodontics - a special issue of the regenerative endodontics - a new era in clinical endodontics. Dentistry Journal. 2016; 4(1):1-15. 
4. Ziętek M., Skrzypczyk I., Szulc M. Comparative analysis and mutual relations between mariginal periodontitis and periapical lesions. literature review. Dent. Med. Probl. 2015; 52(3):265-268.

5. Singh 0., Sinha D., Tyagi S., Tyagi N. Root resorption: challenge to the endodontist. International Jornal of Dental Research and Oral Sciences. 2017; 2(1):31-41.

6. Garcia C., Khouly I., Sanz J., Loomer P. Effectiveness of systemic antimicrobial therapy in combination with scaling and root planning in the treatment of periodontitis : a systematic review. J. Amer. Dent. Assos. 2015; 146(3):150-163.

7. Sculean A. , Nikolidakis D., Nikou G., Biomaterials for promoting periodontal regeneration in human intrabony defects: a systematic review. Periodontology 2000. 2015; 68(1):182-216.

8. Bansal R., Jain A., Mittal S. Current overview on challenges in regenerative endodontics. J. Conserv Dent. 2015;18:1-6.

9. Bartols A., Roussa E., Walther W. First Evidence for Regeneration of the Periodontium to Mineral Trioxide Aggregate in Human Teeth. JOE. 2017; 43(5):715-722.

10. Saoud T., Martin G., Chen Y. Treatment of mature permanent teeth with necrotic pulps and apical periodontitis using regenerative endodontic procedures: A case series. J. Endod. 2016;42(1):57-65.

11. Körklü S., Candaner Y., Özçelik E. Treatment of permanent teeth with extensive apical periodontitis: 2 case reports. British Journal of Medicine and Medical Research. 2016; 17(10):1-7.

12. Saoud T., Huang G., Gibbs J. Management of Teeth with Persistent Apical Periodontitis after Root Canal Treatment Using Regenerative Endodontic Therapy. J. Endod. 2015; 41(10):1743-1748.

13. Kotwal G., Sarojini H., Chien S. Pivotal role of ATP in macrophages fast tracking wound repair and regeneration. Wound Repair Regen, 2015; 23(5):724-727.

14. Khoshbin E., Donyavi Z., Atibeh E. Effect of Nd:YAG and Diode Lasers on Apical Seal of Root Canals Filled with AH Plus and Mineral Trioxide Aggregate-Based Sealers. J Dent (Tehran). 2018; 15(1):30-40.

15. Sokhi R., Sumanthini M., Shenoy V. Effect of Calcium Hydroxide Based Intracanal Medicaments on the Apical Sealing Ability of Resin Based Sealer and Guttapercha Obturated Root Canals. J Clin Diagn. 2017: 11(1):75-79.

16. Zubachyk V., Han I. Comparative evaluation of osteotropic action of endodontic filling materials on the model of experimental destruction of rats' jaw bone tissue. Ukrainian Dental Almanac. 2016;1(2):12-16.

17. Han I., Musij-Sementsiv K., Zubachyk V. The effect of endodontic filling agents on the activity of the regeneration processes of bone tissue in the experiment. JMS. 2018; 87(1):11-18.

18. Zubachyk V.M., Han I.V. Composition for the treatment of complicated caries of permanent teeth with wide foramen apex and at the stage of root formation Pat. 95974, A61K 33/00, A61K 33/06. № u 201408800; appl. 04.08.2014; publ. 12.01.15, Bul. №1.
19. Zubachyk V.M., Han I.V. Pat. 95967, A61C 5/00, A61P 1/02. The method of treatment of complicated caries of permanent teeth with wide foramen apex and at the stage of root formation / № u 201408737; appl. 01.08.2014; publ. 12.01.15, Bul. №1.

20. Kanagasingam S., Lim C., Yong C. et al. Diagnostic accuracy of periapical radiography and cone beam computed tomography in detecting apical periodontitis using histopathological ndings as a deference standard. Int Endod J. 2017; 50(5):417-426.

21. Filho E., Calisto A., Tavarez R. Correlation between the Periapical Index and Lesion Volume in Cone-beam Computed Tomography Images. Iranian Endodontic Journal. 2018; 13(2):155-158.

22. Ricucci D., Siqueira J., Loghin S. Repair of extensive apical root resorption associated with apical periodontitis: Radiographic and histologic observation after 25 years. J. Endod. 2014; 40(8):1268-1274.

23. Orstavic D., Kerekes K., Eriksen M. The periapical index: a scoring system for radiographic assessment of appical periodontitis. Endodontic dental Traumatol, 1986; 2:20-34.

24. Filho E., Calisto A., Tavarez R. Correlation between the Periapical Index and Lesion Volume in Cone-beam Computed Tomography Images. Iranian Endodontic Journal. 2018; 13(2):155-158.

\section{ORCID and contributionship:}

Iryna V. Han: 0000-0003-2605-5029 A,C,F

Volodymyr M. Zubachyk: 0000-0003-3813-5114 ${ }^{\text {B,D }}$

Khrystyna H. Musij-Sementsiv: 0000-0003-3068-8611 F,D

Nataliia I. Bodnaruk: 0000-0002-5222-7915 E,F

Nataliia V. Porokhovska: 0000-0001-5221-8544 ${ }^{\mathrm{C}}$

Oksana M. Slaba: 0000-0003-4566-7178 ${ }^{E}$

\section{Conflict of interest:}

The Authors declare no conflict of interest.

\section{CORRESPONDING AUTHOR Iryna V. Han}

Danylo Halytsky Lviv National Medical University

69 Pekarska St., 79010 Lviv, Ukraine

tel:+380676733304

e-mail: irynagan@gmail.com

Received: 25.10 .2020

Accepted: 01.03 .2021

A - Work concept and design, B - Data collection and analysis, $\mathbf{C}$ - Responsibility for statistical analysis, D-Writing the article, $\mathbf{E}$-Critical review, $\mathbf{F}$-Final approval of the article 